\title{
Manifestaciones muco-cutáneas de la infección por Mycoplasma pneumoniae: Presentación de cuatro casos
}

\author{
Julia Villarroel B., M. Cecilia Bustamante F., Marisol Denegri C. y Lilian Pérez C.
}

\section{Mucocutaneous findings of the Mycoplasma pneumoniae infection: Presentation of four cases.}

The mucocutaneous manifestations of Mycoplasma pneumoniae infection appear in approximately $20 \%$ of all the infections produced by this microorganism. Maculopapular rash, vesicular or urticarial exanthemas, are frequent manifestations that can constitute Erythema multiforme or more rarely, Stevens - Johnson syndrome or epidermal toxic necrolisis. We describe the clinical evolution, diagnosis and treatment of four children with mucous and cutaneous manifestations associated to infection by Mycoplasma pneumoniae and a review of the medical literature.

Key words: Mucositis, Mycoplasma, mucocutaneous manifestations

Palabras clave: Mucositis, Mycoplasma, lesiones mucocutáneas.

\section{Introducción}

$\mathrm{L}$ a infección por Mycoplasma pneumoniae es de ocurrencia universal, afecta tanto a niños como adultos en forma endémica, con brotes epidémicos cada cuatro años, y se presenta durante todo el año ${ }^{1}$.

El compromiso respiratorio es la expresión clínica más frecuente; sin embargo, la infección por M. pneumoniae incluye una extensa variedad de manifestaciones clínicas que pueden comprometer cualquier órgano y que, en muchos casos, representan expresiones de la estimulación del sistema inmune por este microorganismo ${ }^{1}$. Cuando existe compromiso pulmonar, aparecen otras manifestaciones en $30 \%$ de los casos, generalmente dentro de las primeras dos semanas; esta cifra baja a $17 \%$ en ausencia de dicha localización. No está claro si éstas son desencadenadas por acción de toxinas del microorganismo, por efecto de auto-anticuerpos o su invasión directa a los diferentes órganos. Entre estas manifestaciones, una de las más frecuentes son las dermatológicas; también se describen afecciones neurológicas, cardíacas, digestivas, articulares, genitourinarias y oftalmológicas ${ }^{2}$.

El compromiso de piel y mucosas aparece en alrededor de 12 a $20 \%$ de todos los casos que presentan infección por M. pneumoniae ${ }^{2}$ y se manifiesta frecuentemente como lesiones máculo-papulares, vesiculares, urticariales en general de evolución autolimitada, constituyendo, en algunos casos, un eritema multiforme; menos frecuentemente se expresan como síndrome de Stevens-Johnson (SSJ) o como necrosis epidérmica tóxica (NET). También puede manifestarse como eritema nodoso, vasculitis, pitiriasis rosada, etc. En general, se ha observado que las manifestaciones muco-cutáneas se acompañan de compromiso respiratorio simultáneo ${ }^{2}$.

Nos pareció de interés comunicar cuatro casos que se han presentado en nuestro hospital con algunas manifestaciones de piel y mucosas de grado variable, y efectuar una revisión de la literatura.

\section{Casos clínicos}

En un período de dos años ingresaron al servicio de Pediatría de nuestro hospital, cuatro pacientes de sexo masculino que presentaban lesiones extensas de piel y mucosas. Estos niños corresponden al total de pacientes ingresados con lesiones dermatológicas en ese período. Sus edades fluctuaron entre los 2 años y 12 años (promedio 6,8 años). Dos de los niños tenían antecedentes remotos de patología previa (estomatitis y bronconeumonía, respectivamente) y en ninguno de los casos hubo ingesta de medicamentos (Tabla 1),

En todos los casos la sintomatología de inicio fue fiebre, mayor de $38,5^{\circ} \mathrm{C}$ axilar, con una duración de tres a 10 días, tos productiva y aparición de lesiones vesiculosas que, en todos los casos, comprometieron la mucosa oral. En tres casos se presentó además compromiso de la mucosa conjuntival, en dos niños se agregaron lesiones en la mucosa genital y en uno hubo además manifestaciones digestivas (Figuras 1, 3 y 4). Aparecieron lesiones cutáneas en tres de los cuatro pacientes las que fueron diversas: ampollares, en diana, eritematosas y/o polimorfas. Los
Hospital Clínico Félix Bulnes, Santiago, Chile

Servicio de Pediatría Unidad de Infecciosos (JVB, CBF) Unidad de Dermatología (MDC, LPC)

No hay conflictos de interés

Fuentes de financiamiento: propias

Recibido: 8 de abril de 2009

Aceptado: 1 de agosto de 2009

Correspondencia a:

Julia Villarroel Barrera julia.villarroel@vtr.net 


\begin{tabular}{|c|c|c|c|c|}
\hline & Caso 1 & Caso 2 & Caso 3 & Caso 4 \\
\hline Edad & 12 años & 9 años & 2 años & 4 años \\
\hline Sexo & Masculino & Masculino & Masculino & Masculino \\
\hline Días de evolución & 4 & 9 & 5 & 9 \\
\hline Antecedentes mórbidos & Estomatitis & no & Bronconeumonía & no \\
\hline Ingestión de fármacos & no & no & no & no \\
\hline Fiebre (días de evolución) & 3 & 9 & 5 & 10 \\
\hline Compromiso cutáneo & no & $\begin{array}{l}\text { Lesiones ampollares en tronco y } \\
\text { extremidades }\end{array}$ & $\begin{array}{l}\text { Lesiones eritematosas, ampolla- } \\
\text { res, o en diana }\end{array}$ & $\begin{array}{l}\text { Lesiones eritematosas, ampolla- } \\
\text { res y polimorfas extensas }\end{array}$ \\
\hline Compromiso mucoso & Mucosa oral, conjuntival, genital & Mucosa oral, nasal, conjuntival & $\begin{array}{l}\text { Mucosa oral, conjuntival genital, } \\
\text { digestivo }\end{array}$ & Mucosa oral \\
\hline Compromiso pulmonar & Consolidación basal derecha & Consolidación basal derecha & Imágenes intersticiales bilaterales & no \\
\hline Signo de Nikolsky & $(-)$ & $(+)$ & $(-)$ & $(+)$ \\
\hline$\%$ de piel comprometida & $0 \%$ & $10 \%$ & $10 \%$ & $30 \%$ \\
\hline Leucocitos en sangre/mm³ & 7.500 & 15.500 & 8.700 & 15.500 \\
\hline Desviación a izquierda & no & no & no & no \\
\hline VHS & 50 & 117 & 23 & 12 \\
\hline PCR & 192 & 87 & 39 & 11 \\
\hline $\lg M(E \mid A)$ & 39 & 24,3 & 30 & 25 \\
\hline Antimicrobianos & Claritromicina & Claritromicina & Eritromicina & Claritromicina \\
\hline Antihistamínicos & Clorfenamina & no & no & no \\
\hline Corticosteroides & Betametasona & no & no & no \\
\hline IGEV & no & no & no & $2 \mathrm{gr} / \mathrm{kg} / 1 \mathrm{vez}$ \\
\hline Diagnóstico final & $\begin{array}{l}\text { Mucositis extensa, neumonía } \\
\text { basal derecha }\end{array}$ & $\begin{array}{l}\text { S. Stevens-Johnson, neumonía } \\
\text { basal derecha }\end{array}$ & $\begin{array}{l}\text { Eritema multiforme, neumonía } \\
\text { intersticial }\end{array}$ & Necrolisis epidérmica tóxica \\
\hline
\end{tabular}

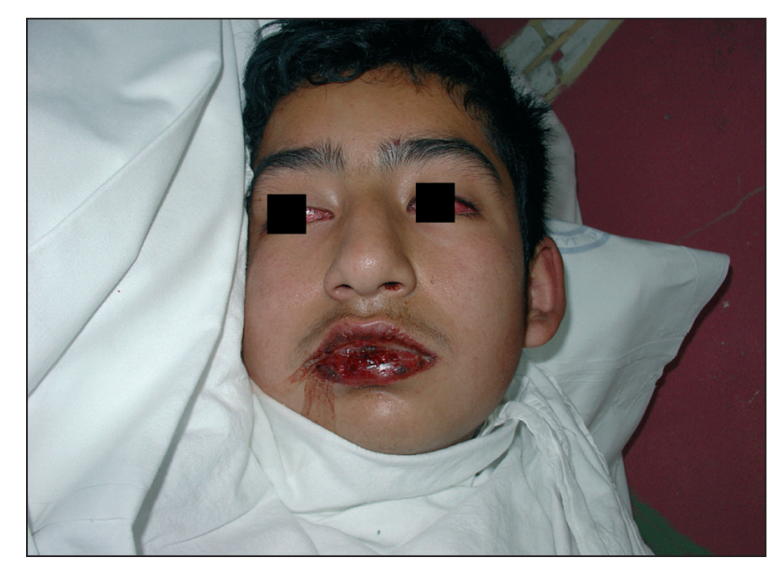

Figura 1. Caso 1. Lesiones ampollares y costras en la mucosa oral asociado a eritema conjuntival.

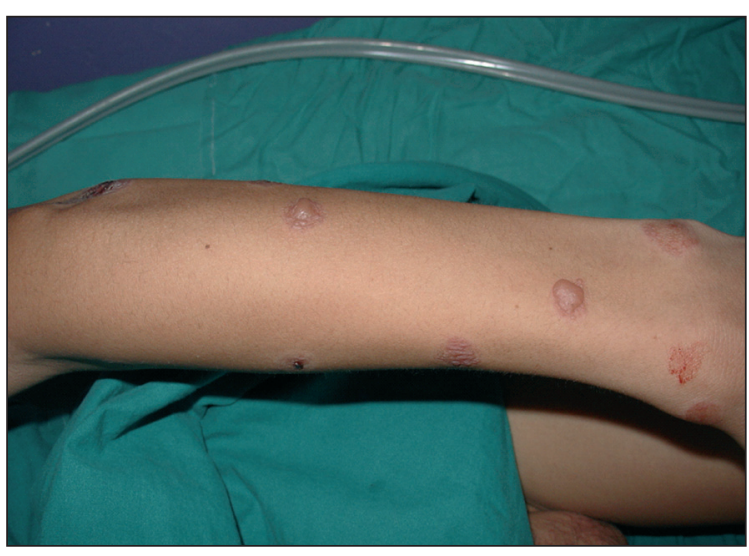

Figura 2. Caso 2: Extensas lesiones ampollares. 
diagnósticos fueron mucositis, SSJ, eritema multiforme y NET (Figuras 1, 2, 3 y 6). Se presentó compromiso pulmonar en tres de los cuatro niños, el que se manifestó como foco de consolidación basal derecho en dos casos y en el tercero sólo hubo compromiso intersticial bilateral. (Tabla 1).

Los exámenes de laboratorio tomados al ingreso mostraron leucocitosis mayor de $15.000 / \mathrm{mm}^{3}$ en dos casos, pero sin desviación a izquierda; la VHS mostró elevación variable, en rango de 23 a $117 \mathrm{~mm} / \mathrm{h}$ (promedio $57 \mathrm{~mm} / \mathrm{h}$ ) y la proteína $\mathrm{C}$ reactiva (PCR) presentó grandes fluctuaciones desde valores en rango normal a niveles sugerentes de infección bacteriana ( $>90 \mathrm{mg} / \mathrm{lt}$ ). Se sospechó como agente etiológico $M$. pneumoniae, por lo cual, en todos los pacientes se efectuó IgM específica para micoplasma por método de EIA (enzimoinmunoanálisis), (Kit Novatec) cuyos rangos variaron entre 24,3 y $39 \mathrm{UE}$, todos considerados positivos (punto de corte $>11 \mathrm{U}$ ), (Tabla 1), exámenes obtenidos entre el $7^{\circ}$ y $13^{\circ}$ día de evolución de la sintomatología. No fue posible efectuar estudio de otros agentes etiológicos como herpes simplex, enterovirus, virus de Epstein-Barr o parvovirus B19 por falta de financiamiento. El tratamiento anmicrobiano incluyó macrólidos (eritromicina o claritromicina) durante 10 días. En un caso se adicionó antihistamínicos (clorfenamina) y corticosteroides endovenoso (betametasona). En otro caso se usó inmunoglobulina endovenosa (IGEV) en una dosis de 2 gr/kg por una vez, debido al gran compromiso ampollar de piel y mucosas, lo que fue interpretado como una NET. La evolución fue favorable en todos los pacientes lográndose la desaparición de las lesiones de piel y mucosas en un plazo variable de 10 a 20 días. No se presentó compromiso de otros sistemas (hepático, renal, $\mathrm{SNC}$, etc) ni hubo fallecidos.

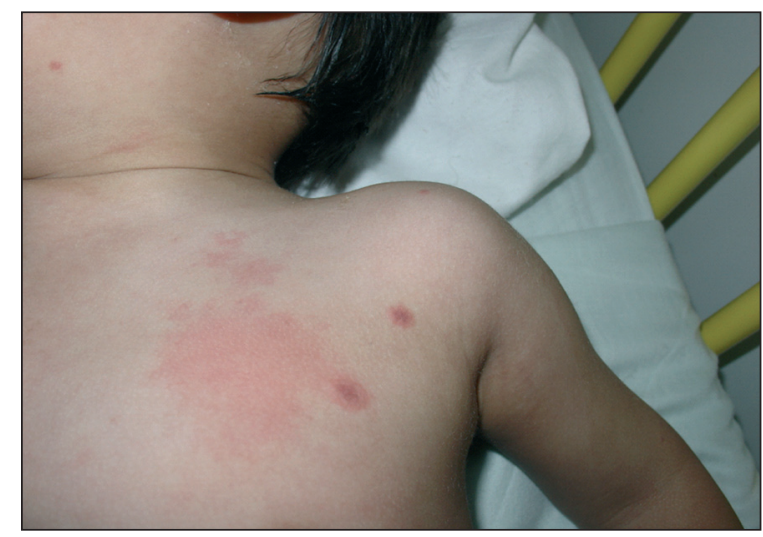

Figura 5. Caso 3: Lesiones en tiro al blanco o diana ("target") en región anterior de tórax.

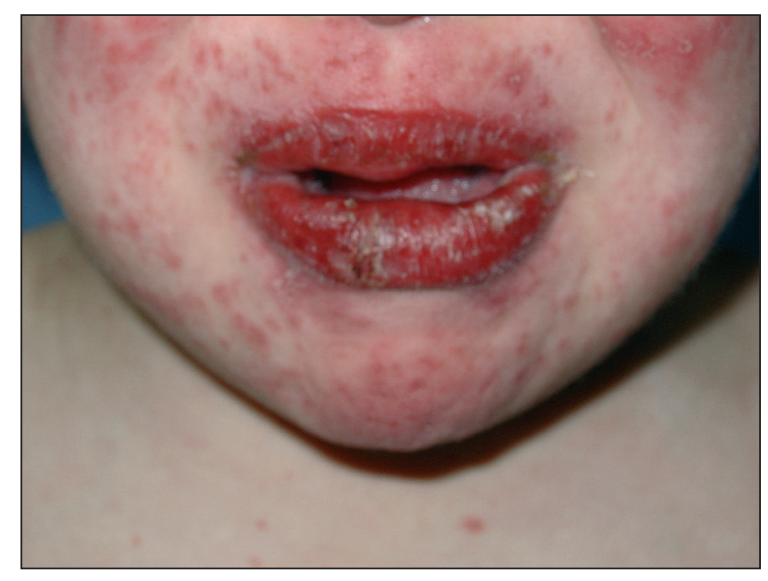

Figura 3. Caso 3: Extensas lesiones ampollares en la mucosa oral y pápulas faciales.

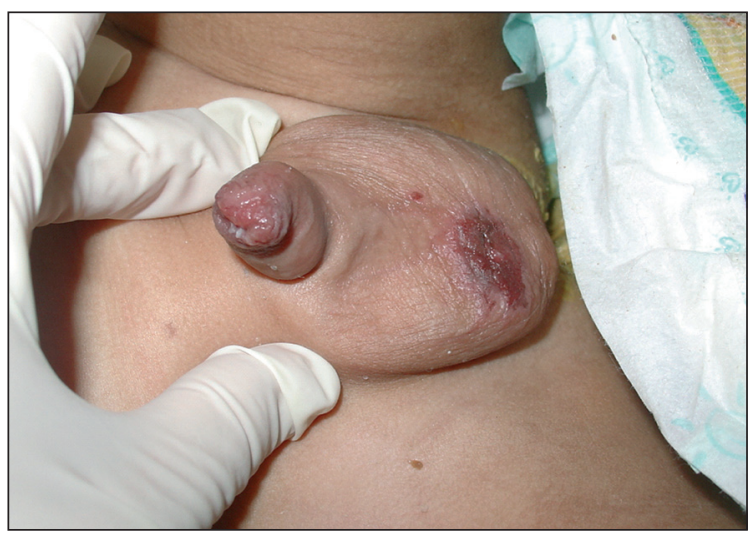

Figura 4. Caso 3: Erosiones y costras en la piel del escroto y en la mucosa genital.

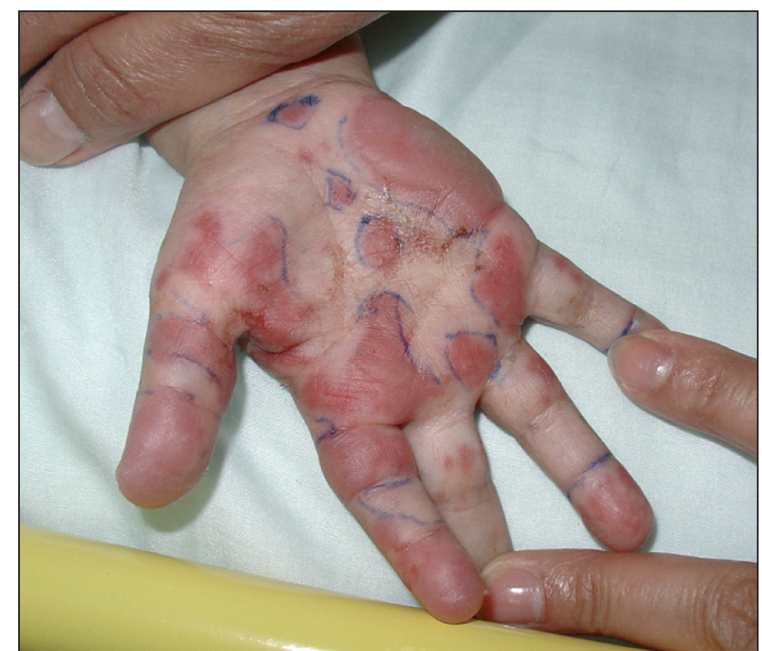

Figura 6. Caso 4: Lesiones ampollares y pápulas eritematosas en palma de manos. 


\section{Discusión}

Los micoplasmas representan los agentes bacterianos más pequeños conocidos hasta ahora con capacidad patogénica para el hombre. Pertenecen a la familia Mycoplasmataceae, la que está constituida por dos géneros Mycoplasma y Ureaplasma. Dentro del género Mycoplasma hay 16 especies patógenas para el hombre, entre las cuales se encuentra M. pneumoniae ${ }^{1}$.

En general, son anaerobios facultativos, aparecen en los cultivos en agar con el característico aspecto de las colonias: presentan un centro más denso y oscuro y una zona periférica más clara, lo que se ha denominado aspecto de "huevo frito". Mycoplasma pneumoniae -la excepción- es aerobio estricto y sus colonias tienen un aspecto más homogéneo y granular ${ }^{1-4}$.

Frecuentemente causan infecciones del tracto respiratorio, siendo el hombre el único reservorio conocido. Estudios serológicos han permitido estimar que se producen entre 11 y 15 millones de infecciones anuales por micoplasmas en el mundo ${ }^{5}$. Únicos estudios latinoamericanos, efectuados en Argentina y Panamá, revelan una prevalencia de infección respiratoria baja por $M$. pneumoniae de 15 y $7 \%$ respectivamente ${ }^{6,7}$. En Chile no se conoce la prevalencia de esta infección; sin embargo, una investigación efectuada en consultorios de atención primaria de la Región Metropolitana (comunas de Maipú y La Florida) buscó la presencia de M. pneumoniae en secreción faríngea utilizando reacción de polimerasa en cadena (RPC), en niños asintomáticos y encontró $2 \%$ de portación faríngea ${ }^{8}$. Hasta hace un tiempo se estimaba que las edades más afectadas eran los escolares y los adultos jóvenes; sin embargo, en los últimos años, se ha visto que las infecciones por este microorganismo se producen más precozmente, ya antes de los tres años de vida ${ }^{9}$. Esto se evidenció en dos de nuestros pacientes, en los cuales, la infección se presentó en un lactante mayor (dos años) y en un preescolar (cuatro años).

Las manifestaciones extra-pulmonares de la infección por M. pneumoniae se presentan en $\sim 25 \%$ de los casos y pueden aparecer antes, durante o después de una infección pulmonar, e incluso en ausencia del compromiso pulmonar; dentro de este grupo, las lesiones de piel y mucosas son frecuentes 9 . Habitualmente, el compromiso cutáneomucoso típico se expresa como exantema máculo-papular, vesiculoso o urticarial, generalmente autolimitados, aunque en algunos casos conforma un eritema multiforme y más raramente SSJ $(1 \text { a } 5 \%)^{10}$ o NET, también denominado síndrome de Lyell. En raros casos se ha descrito infección por M. pneumoniae asociada a angioedema no episódico, púrpura de Schoenlein-Henoch y vasculitis leucocitoclástica ${ }^{11}$. La vasculitis de piel es una inusual manifestación de la infección por micoplasma y se ha reportado en la literatura en contadas oportunidades (seis casos) una de los cuales se asoció a compromiso retinal ${ }^{12}$. El SSJ y la NET son parte de un mismo espectro clínico y generalmente se acompañan de un cuadro respiratorio, el que puede ser ocasionado por micoplasma en $\sim 1$ a $5 \%$ de los $\operatorname{casos}^{9,10}$. También se han descrito casos de neumonías por M. pneumoniae asociadas a enfermedad de Kawasaki, eritema nodoso, exantema ampollar, angioedema no episódico, y otros ${ }^{11-15}$.

Patogenia de las lesiones mucocutáneas. El eritema multiforme rara vez se asocia a alergenos o a fármacos; en $90 \%$ de los casos es secundario a infección por virus herpes simplex o por micoplasma. Se produce por una respuesta inmune citotóxica dirigida contra los queratinocitos que expresan antígenos extraños e involucra daño a los vasos sanguíneos de la piel con la subsecuente destrucción tisular. Aparecen lesiones máculo-papulares que presentan un centro rojo, rodeadas periféricamente por un anillo pálido y un segundo anillo externo oscuro, (lesión en diana o target) las que se distribuyen en las palmas y plantas a lo largo de las extremidades, siendo inusual el compromiso del tronco. También se pueden observar lesiones de tipo ampollar y en algunos pacientes se produce compromiso de mucosas, siendo la mucosa oral la más frecuentemente comprometida. Presenta baja morbilidad y nula mortalidad. Se resuelve en un plazo variable de alrededor de un mes, situación que se evidenció en nuestros pacientes ${ }^{16}$.

El SSJ tiene una incidencia de 0,4 a 1,2 casos por millón de habitantes por año y la NET tiene una incidencia de 1,2 a 6 casos por millón de habitantes por año ${ }^{17}$. Ambos están íntimamente relacionados y son casi idénticos salvo por el porcentaje de compromiso de la superficie corporal (de menos del $10 \%$ en SSJ y mayor al $30 \%$ en la NET). Tanto en el SSJ como en la NET se encuentra gran cantidad de macrófagos y linfocitos CD8 en la epidermis afectada y estos reaccionarían frente a antígenos o a fármacos ${ }^{17,18}$. Los queratinocitos normales expresan en su superficie el antígeno soluble CD95 (Fas) que se une a un ligando de Fas (s Fas L) generando la apoptosis normal. En los pacientes con NET se han encontrado concentraciones normales de Fas, pero grandes cantidades de s-Fas L en los queratinocitos; esto origina una intensa apoptosis de todas las capas de la epidermis. Por otra parte, hay gran liberación de factor de necrosis tumoral, interferon gama, e interleuquinas (IL5, IL6, IL10 e IL13) que intensifican aún más la apoptosis, al elevar las concentraciones de s-Fas-L $\mathrm{L}^{17,18}$.

En ambos síndromes (SSJ y NET) la sintomatología es muy similar, de inicio brusco, con fiebre, malestar general, compromiso respiratorio, cefalea, odinofagia, vesículas y ampollas en la cavidad oral y en otras mucosas, ya sea conjuntival, genital, digestiva o respiratoria. Posteriormente, aparecen pseudo-membranas, sialorrea y ulceraciones que dificultan la ingestión de alimentos, al igual 
que lo ocurrido en todos nuestros pacientes. Las lesiones cutáneas se presentan en forma simétrica en la superficie de extensión de las extremidades, zona glútea y tronco, luego se hacen confluentes y muestran el signo de Nikolsky $(+)$ : desprendimiento y separación de la epidermis al presionar la piel, debido a la separación previa existente entre la dermis y la epidermis. Este signo puede estar presente en otras patologías como pénfigos y penfigoides auto-inmunes. El compromiso de las superficies flexoras es menos frecuente. En general, las lesiones evolucionan hacia la mejoría en un plazo variable de 1 a 4 semanas, aunque se describe en algunos casos lesiones mucosas persistentes por varios meses y que eventualmente pueden dejar secuelas ${ }^{17,18}$. La NET es la expresión más grave de este proceso inmunológico; inicialmente se aprecia la piel enrojecida dolorosa, semejante a una quemadura solar, el eritema es oscuro, luego aparecen lesiones en diana (o tiro al blanco) y ampollas, las que se diseminan con rapidez provocando un desprendimiento de la epidermis y queda la dermis al descubierto, lo que origina grandes pérdidas proteicas, desequilibrio hidro-electrolítico, alteraciones en la termo-regulación y se favorecen las sobre-infecciones ${ }^{15-19}$. Esta situación se evidenció en el cuarto caso, el cual se trató como un gran quemado y se administró IGEV. Puede estar asociado a conjuntivitis, úlceras corneales, retinitis, uveítis anterior, exudados retinales, hemorrágicos y neuropatías del nervio óptico; en nuestros casos el compromiso de la mucosa ocular se expresó sólo como conjuntivitis ${ }^{20,21}$.

Como se mencionó anteriormente, la diferencia entre SSJ y NET está dada por la extensión del compromiso de piel y por la profundidad, ya que en el SSJ sólo hay compromiso de la epidermis y en la NET se compromete además la dermis ${ }^{15,17-19}$.

En la literatura médica reciente se han reportado casos esporádicos de neumonía por $M$. pneumoniae con mucositis aislada, pero carentes de lesiones de piel. En estos casos, el diagnóstico es más difícil, dado que un número importante de otras patologías pueden manifestarse con cambios en las mucosas, incluyendo enfermedades infecciosas producidas por virus mucotrópicos como enterovirus, herpes simplex y virus de Epstein-Barr, enfermedades auto-inmunes, reacciones a fármacos, etc ${ }^{17,18,21-25}$. En uno de nuestros casos la infección se expresó sólo con compromiso de varias mucosas (oral, conjuntival, nasal y genital) asociado a un proceso neumónico consolidante.

Diagnóstico de laboratorio. Los micoplasmas activan varios componentes del sistema inmune, las células B y linfocitos T, con la consiguiente estimulación de citocinas pro-inflamatorias y aumento importante en la producción de anticuerpos, algunos con función neutralizante y otros de tipo auto-anticuerpos como las aglutininas contra pulmón, cerebro, músculo liso, etc.; los más importantes y conocidos son las crio-aglutininas dirigidas contra el antígeno "Y" de los eritrocitos. Los niveles de crioaglutininas se elevan entre la primera y segunda semana de infección y son inespecíficos, apareciendo sólo en 50\% de los casos. Se utilizaron bastante para el diagnóstico de la infección y anteriormente se consideraba que títulos superiores a 1:64 eran positivos. Actualmente, se prefieren técnicas que permitan medir niveles de anticuerpos específicos como la técnica de EIA, la que fue efectuada en nuestros pacientes ${ }^{26}$.

La respuesta inmunológica a micoplasma es variable de una persona a otra, lo que condiciona el daño tisular; a mayor vigor en la respuesta inmune mediada por células e interleuquinas, mayor es el daño tisular. Por otra parte, la inmunidad del hospedero no bloquea de manera efectiva la adherencia celular del micoplasma, lo que explica las altas tasas de re-infección observadas ${ }^{4}$. En la primera infección se produce una rápida elevación de IgA específica, previa a la elevación de $\operatorname{IgM}$ específica. Los títulos de IgM suben alrededor de los siete días de comenzada la sintomatología, precediendo en dos semanas a la IgG, alcanzan una elevación máxima entre las 4 y 6 semanas, y luego caen lentamente hasta desaparecer entre 14 y 6 meses desde iniciada la infección; sin embargo, la primoinfección no deja inmunidad duradera ${ }^{26-29}$.

En las re-infecciones, en general no hay respuesta de IgM, sino un rápido aumento de la $\operatorname{IgG}$ que se acompaña de aumento en la producción de $\operatorname{IgA}$. En algunas reinfecciones se produce elevación de IgM, la que puede persistir por meses o años, de modo que en el adulto joven la detección de IgM no implica infección reciente. Por lo anterior, las técnicas de detección de IgM tienen una buena sensibilidad y especificidad en la primoinfección, mientras que en las re-infecciones no permiten descartar una infección reciente. En los niños mayores y adultos se recomienda la determinación de $\operatorname{IgA}$ e $\operatorname{IgG}^{29}$.

Las primeras determinaciones de anticuerpos se realizaron por técnica de fijación del complemento (FC) que mide predominantemente anticuerpos IgM y sólo una pequeña cantidad de anticuerpos IgG, por lo que el valor diagnóstico de la FC es muy sensible en la primoinfección por este microorganismo. Títulos superiores a 1/32 proporcionan una sensibilidad de $90 \%$ y una especificidad de $88 \%$, no así en las re-infecciones ${ }^{29}$.

La técnica de EIA usada actualmente, permite detectar IgM o IgG, y se ha visto que en población pediátrica basta identificar la IgM en la fase aguda. La sensibilidad de esta técnica varía entre 42 y $67 \%$ para la muestra en fase aguda y entre 75 y $100 \%$ para muestras de fase aguda y crónica combinadas. La especificidad es de $98 \%{ }^{25-29}$.

La RPC en exudado faríngeo está cobrando cada vez mayor importancia, por ser rápida, sensible y específica para $M$. pneumoniae. Tiene una sensibilidad de $75 \%$ y una especificidad de $97 \%$. Es importante recordar que se ha descrito la presencia de $M$. pneumoniae en secreción fa- 
ríngea de individuos sanos (asintomáticos) lo que le resta valor clínico a la pesquisa. La RPC ha demostrado ser útil para el diagnóstico de infecciones por este microorganismo en niños inmunodeprimidos y en lactantes menores. Al combinar RPC e IgM en fase aguda la sensibilidad aumenta a $100 \%$, situación que estuvo fuera del alcance de nuestros pacientes por el costo que ello representa ${ }^{28-32}$.

Las técnicas de cultivo son caras, laboriosas, lentas y no son abordables para la mayoría de los laboratorios clínicos. Su sensibilidad no es mayor a $60 \%$ pero la especificidad es de $100 \%{ }^{29,32}$.

La infección por este microorganismo no muestra alteraciones específicas en la serie leucocitaria del hemograma; se describe que en un tercio de los casos puede haber leucocitosis, situación que se evidenció en nuestros niños ${ }^{32}$.

Considerando que la condición dermatológica es fácil de establecer desde el punto de vista clínico, la biopsia de piel tendrá indicación sólo en casos excepcionales. Tratándose de un eritema multiforme, la biopsia muestra dermatitis de interfase, con queratinocitos necróticos, licuefacción de la capa basal, infiltrado inflamatorio mixto con predominio de linfocitos $\mathrm{T}$ y separación de la unión dermo-epidérmica que puede llevar a la formación de ampollas. En el SSJ y NET se aprecian los mismos fenómenos más una necrosis epidérmica total con una dermis relativamente poco afectada ${ }^{33}$.

En el diagnóstico diferencial se deben considerar otras causas de mucositis oral intensa, como Kawasaki, gingivo-estomatitis herpética, herpangina, enfermedad mano pie boca, y más raros, pénfigo vulgar y enfermedad de Behcet.

Tratamiento especifico y sintomático. Mycoplasma pneumoniae es susceptible a antimicrobianos que actúan en la síntesis proteica, como son macrólidos, tetraciclinas y quinolonas. Los macrólidos, utilizados en nuestros pacientes, producen mejoría clínica y erradicación microbiológica. Se prefiere actualmente utilizar macrólidos nuevos como claritromicina o azitromicina, por su cómoda posología y mejor tolerancia digestiva. Los corticosteroides, en aplicación tópica como sistémica, son indicados en los casos de eritema multiforme; sin embargo, en los casos de SSJ o NET su uso, ha sido controvertido en el último tiempo. Según algunos estudios sería ventajoso utilizarlos en las etapas tempranas de la enfermedad y deletéreo en las tardías. No se ha demostrado su eficacia en ensayos clínicos controlados ${ }^{34}$. En la NET el uso de IGEV sería beneficioso, ya que, proporciona anticuerpos contra el Fas, bloqueándolo y por lo tanto deteniendo la intensa apoptosis que se produce al impedir la unión de Fas y s-Fas L en los queratinocitos ${ }^{34-36}$. Esto lo pudimos apreciar en nuestro caso, el que mostró franca mejoría del estado general y del compromiso muco-cutáneo después del uso de IGEV

Con respecto a las complicaciones y mortalidad, ausentes en nuestros niños, el eritema multiforme puede ser recurrente pero no presenta mortalidad, en el SSJ y en la NET se pueden comprometer otros sistemas como el respiratorio, renal, SNC o hepático y la mortalidad es frecuencia variable: en el SSJ alrededor de $5 \%$ y en la NET fluctúa entre 30 y $40 \%{ }^{37}$.

El compromiso muco-cutáneo dado por M. pneumoniae es una entidad que exige un diagnostico precoz, especialmente en las formas más graves. Además, es importante saber reconocerlo y diferenciarlo de otras etiologías infecciosas y/o farmacológicas. Del mismo modo nos parece fundamental investigar la real dimensión del problema en nuestro país.

\section{Resumen}

El compromiso muco-cutáneo de la infección por Mycoplasma pneumoniae se presenta en aproximadamente $20 \%$ de todas las enfermedades producidas por este microorganismo. Frecuentemente se manifiesta con lesiones máculo-papulares, vesiculosas o urticariales, que pueden constituir el eritema multiforme, más raramente síndrome de Stevens-Johnson o necrosis epidérmica tóxica. Describimos la evolución clínica, diagnóstico y el tratamiento administrado a cuatro niños que presentaron manifestaciones de piel y mucosas en relación a la infección por Mycoplasma pneumoniae. Se efectuó además una revisión de la literatura médica.

\section{Referencias}

1.- Baum S. Capítulo 162. Mycoplasma Diseases. En Mandell, Douglas and Bennett's Principles and Practice of Infectious Diseases. Mandell GL, Bennett JE\& Dolin R, eds. $6^{\text {th }}$ Ed. 2006. Churchill Livingstone Inc; Philadelphia, pp 2015-27.

2.- Waites K. New concepts of Mycoplasma pneumoniae infections in children. Pediatr Pulmonol 2003; 36: 267- 78 .
3.- Waites K, Taligngton D. Mycoplasma pneumoniae and its role as a human pathogen. Clin Microbiol Rev 2004; 17: 697-728

4.- Carreazo J. Fisiopatología de las infecciones por Mycoplasma pneumoniae. Paediatrica 2003; 5 (2): 101-8

5.- González-Zárate P. Infecciones por Mycoplasma. Medicine 2002; 66 (8): 3512-14.

6.- Ferrero E, Osorio M, Eriksson P, Durán A. Mycoplasma pneumoniae en niños con neumonía. Arch Argent Pediatr 2000; 98: 12-7.
7.- Sáez-Llorens X, Castaño E, Wubbel L, Castrejon M, De Morales I, Vallarino D, et al. Importancia de Mycoplasma pneumoniae y Chlamydia pneumoniae en niños con neumonía adquirida en la comunidad. Rev Méd Panamá 1998; 23: 27-33.

8.- Palma C, Martínez M A, Salinas M, Rojas P. Portación faríngea de Mycoplasma pneumoniae en niños chilenos. Rev Chil Infect 2005; 22 (3): 247-50. 
9.- Paul M, García C, Vega-Briceño L. Infección por Mycoplasma pneumoniae. Neumología Pediátrica 2007; 2 (3): 140- 6.

10.- Ravin K, Rappaport L, Zuckerbraun N, Wadosky R, Wald E, Micheals M. Mycoplasma pneumoniae and atypical Stevens-Johnson Syndrome: A case series. Pediatrics 2007; 119: 1002-5.

11.- Gómez-Campdera J, Alonso R, Navarro M, Sanz E, Dobón P, Rodriguez R. Manifestaciones dermatológicas de la infección por Mycoplasma pneumoniae. Acta Pediatr Esp 2006; 64 (9): 446-52.

12.- Greco F, Sorge A, Salvo V, Sorge G. Cutaneous vasculitis associated whith Mycoplasma pneumoniae infection: Case report and literature review. Clin Pediatr (Phila) 2007; 46: 451-3.

13.- Corral M, Arranz D, Vera E, Vidaurrázaga C, Casado M. Vasculitis leucocitoclástica cutánea debida a infección por Mycoplasma pneumoniae. Rev Chil Dermatol 2005; 21 (2): 102-3.

14.- Pardes R, Wadowksy R. Rhabdomyolysis associated with infection by Mycoplasma pneumoni$a e$ : A case report. Pediatrics 2000; 105: 433-6.

15.- Stockner I, Thaler J, FichtelG, Egarter-Vigl E, Wallnoffer W, Wiedermann C. Non-episodic angioedema associated with eosinophilia following Mycoplasma pneumoniae infection. Clin Rheumatol 2008; 27: 1573-6.

16.- Schalock P, Dinulos J, Pace N, Schwarzenberger $\mathrm{K}$, Wenger J. Erythema multiforme due to $M y$ coplasma pneumoniae infection in two children. Pediatr Dermatol 2006; 23 (6): 546-55.

17.- Modesto M, Reyes S, Calabuig E, Nauffal D. Síndrome de Stevens-Johnson asociado a neumonía atípica. Arch Bronconeumol. 2003; 39 (8): 373-5.

18.- Borchers A, Lee J, Naguwa S, Cheema G, Gershwin M. Stevens-Johnson syndrome and toxic epidermal necrolysis. Autoimmun Rev 2008 (7): 598-605.

19.- Aburto C, Torres R, Caro A, Salinas E. Síndrome de Stevens-Johnson asociado a infección por Mycoplasma pneumoniae y virus herpes simplex. Folia Dermatol 2005; 16 (2): 81-4.

20.- Salzman M, Sood S, Slavin M. Ocular manifestations of Mycoplasma pneumoniae infection. Clin Infect Dis 1992; 14: 1137- 9.

21.- Milla E, Zografos L, Piguet B. Bilateral optic papillitis following Mycoplasma pneumoniae pneumonia. Ophthalmologica 1998; 212: 344-6.

22.- Fearon D, Hesketh E, Mitchell A, Grimwood Ket. Mycoplasma pneumoniae infection complicated by pneumomediastinum and severe mucositis. J Paediat Child Health 2007; 43 (5): 403-5.

23.- Latsch K, Girschick J, Abele-Horn M. StevensJohnson syndrome without skin lesions. J Med Microbiol 2007; 56: 1696-9.

24.- Vantleteren L, Van Gysel D, De Brandt C. Stevens-Johnson syndrome: a diagnostic challenge in the absence of skin lesions. Pediatr Dermatol 2003; 20: 52-6.

25.- Schalock P, Dinulos J. Mycoplasma pneumoniae induced Stevens-Johnson syndrome without skin lesions. J Am Acad Dermatol 2005; 52: 312-5.

26.- Csangó P, Pedersen J, Hess R. Comparison of four Mycoplasma pneumoniae IgM-,IgG- and IgA-specific enzyme immunoassays in blood donors and patients. Clin Microbiol Infect 2004; 10: 1094-8.

27.- Souliqu E, Almasri M, Papa A, Theodoridou A, Diza E. Laboratory diagnosis of Mycoplasma pneumoniae respiratory tract infections in Children. Eur J Clin Microbiol Infect Dis 2007; 26: 513-5.

28.- Daxboeck F, Krause R, Wenisch C. Laboratory diagnosis of Mycoplasma pneumoniae infection.
Clin Microbiol Infect 2003; 9: 263-73.

29.- Matas L, Molinos S, Fernández G, González V, Ausina N. Diagnóstico serológico de las infecciones por Mycoplasma pneumoniae. Enferm Infecc Microbiol Clin 2006; 24: 19-23.

30.- Martínez M, Pino Y, Salazar T, Yover E, Caroca C, Espinoza M, et al. Utilidad de la reacción de polimerasa en cadena para la detección de Mycoplasma pneumoniae en adultos mayores con neumonía adquirida en la comunidad. Rev Chil Infect 2005; 22 (3): 251-6.

31.- Templeton K E, Scheltinga S A, Graffelman A W, Van Schie J M, Crielaard J W, Sillekens P, et al. Comparison and evaluation of real-time PCR, real-time nucleic acid sequence-based amplification, conventional PCR, and serology for diagnosis of Mycoplasma pneumoniae. $\mathrm{J}$ Clin Microbiol 2003; 41: 4366-71.

32.- Murray H, Tuazon C. Atypical pneumonias. Med Clin North Am 1980; 64: 507-27.

33.- Melloni L, Padron A, Larrazabal L, Sony B. Necrolisis epidérmica tóxica inducida por fármacos. Caso clinico. Cir Plast Iberolatinoam 2008; 34 (4): 305-12.

34.- Gatti C, Rodríguez M, Cha D, Barquín M A. Necrolisis epidérmica tóxica inducida por lamotrigina: tratamiento con inmunoglobulina endovenosa. Med Cutan Ibero-latinoam 2003; 31 (3): 182-6.

35.- Redman D, Friedman B, Still J, Law E, Still J. The use of immune globulin $\mathrm{G}$ in the treatment of toxic epidermal necrolysis. Crit Care Med 2004; 32 supl A36.

36.- Khalili B, Bahna S. Pathogenesis and recent therapeutic trends in Stevens-Johnson syndrome and toxic epidermal necrolysis. Ann Allergy Asthma Immunol 2006; 97 (3): 272-80.

37.- Stern R. Improving the outcome of patients with toxic epidermal necrolysis and Stevens-Johnson syndrome. Arch Dermatol. 2000; 136 (3): 410-1. 